\title{
Contingencia y finalidad. \\ Kant y la perspectiva reflexiva sobre la naturaleza
}

\section{Contingence and Teleology. Kant and the Reflective Perspective on Nature}

\author{
Alejandro G. Vigo \\ Universidad de Navarra, España \\ avigo@unav.es \\ Recibido: 14/04/2016 • Aceptado: 11/08/2016
}

\begin{abstract}
Resumen
Este trabajo sigue de cerca la exposición de la segunda parte de la Crítica del juicio de Immanuel Kant para valorar la novedad que supone la aportación de su peculiar exposición de la necesidad y la contingencia, en la que en vez de enfrentarse, cabe su coincidencia en la consideración de la naturaleza como un sistema de fines, al tiempo que como un mecanismo movido por causas eficientes. En efecto, al contemplar la posibilidad de la concordancia, en la naturaleza, entre las leyes, objetivas, y las máximas, subjetivas, el juicio reflexivo de la facultad de juzgar permite tratar la naturaleza como si fuera un sistema de fines, en analogía con la teleología propia de la humana libertad. Semejante tratamiento de la teleología permite a Kant plantear una teología en concordancia con la tradición filosófica clásica.
\end{abstract}

Palabras clave: facultad del juicio, juicio reflexivo, Kant, teleología, teología.

\section{Abstract}

This work follows closely the second part of Immanuel Kant's Critique of Judgement to value the novelty of his peculiar approach to necessity and contingency, which he does not think of as opposed, but as coincident in relation to the consideration of Nature as a system of endings; while, at the same time, he thinks of it as a mechanism driven by efficient strengths. Indeed, when considering the possibility of concordance between objective laws and subjective maxims, in Nature, the reflexive judgement of the 
faculty of judgment allows to treat it as if it was a system of endings, in analogy with a theology adequate for human freedom Such an approach to teleology allows Kant to draw a Theology in accordance with the classical philosophical tradition.

Keywords: judgment, Kant, reflective judgments, teleology, Theology. 


\section{Introducción}

En el presente trabajo tomaré en consideración un aspecto específico de la concepción del juicio teleológico presentada por Kant en la segunda parte de Kritik der Urteilskraft (KU) (Kant, 2001). ${ }^{1}$ Se trata, concretamente, del aspecto que concierne a la aportación que realiza el juicio reflexivo en la consideración de la naturaleza, desde la perspectiva propia que corresponde a lo que Kant denomina un «enjuiciamiento teleológico» (teleologische Beurteilung). A este aspecto preciso alude el subtítulo del trabajo. El título refiere, en cambio, a la conexión entre contingencia y finalidad. Ello se debe al hecho de que, a diferencia de muchas de las concepciones más difundidas, que suelen establecer un contraste irreconciliable, o poco menos, entre contingencia y finalidad, Kant establece cierto tipo de conexión estructural entre ambas, pues constata que una determinada forma de experiencia de la contingencia se encuentra, por así decir, en la base del peculiar tipo de reflexión que se orienta por medio de la referencia a fines y, en cierto modo, la motiva y la inicia o dispara. Como se verá, este modo de afrontar el problema permite dar cuenta incluso de la dimensión teológica que en último término, y solo en último término, alcanza necesariamente, a juicio de Kant, la consideración teleológica de la naturaleza.

Dividiré la discusión de la concepción elaborada por Kant en tres partes. En primer lugar (sección 3), presentaré el modo en el que Kant piensa la conexión entre contingencia y finalidad. A continuación (sección 4), consideraré la posición de Kant respecto de la estructura, la función y el alcance que posee el enjuiciamiento teleológico, allí donde se trata de dar cuenta de la posibilidad y la presencia en la naturaleza de lo que el propio Kant denomina «fin(es) de la

1 Cito la obra por la paginación de la segunda edición del texto original, publicada a fines de 1792, con fecha de 1793. 
naturaleza» (Naturzweck(e)). Por último (sección 5), haré unas pocas referencias, muy breves, a la cuestión relativa a la dimensión teológica que adquiere la consideración teleológica de la naturaleza. Pero, antes de abordar el texto de Kant, comenzaré con algunas indicaciones, muy generales, sobre el problema que plantea la oposición de contingencia y finalidad, tal como ha sido abordado en la tradición filosófica que remonta a Platón y Aristóteles (sección 2).

\section{El problema de la relación entre contingencia y finalidad}

Simplificando mucho las cosas, se puede decir que hay un modo tradicional, dominante incluso hasta el presente, de abordar el ámbito de problemas vinculado con las nociones de contingencia y finalidad, que asume el carácter poco menos que irreconciliable de ambos términos, como si la suposición básica de la que se partiera aquí fuera más o menos la siguiente: "donde hay contingencia y, en particular, azar, allí no hay finalidad, y viceversa, donde hay finalidad, allí no hay contingencia ni azar". Naturalmente, esto está dicho aquí sin los necesarios matices, pues muchas veces se intenta mitigar el contraste así establecido introduciendo restricciones, ya sea de grado o bien de alcance, de los ámbitos propios de la contingencia y el azar, por un lado, y de la finalidad, por el otro. Por caso, se suele admitir que en el ámbito del obrar humano tenemos, ciertamente, fenómenos teleológicos específicos, vinculados con el carácter intencional de la acción humana. Éstos aparecen conectados, sin embargo, con una multitud de factores contingentes y azarosos, en la medida en que el obrar humano debe realizarse en un mundo exterior que le viene dado de antemano, y que está poblado de una inmensa variedad de factores causalmente eficaces, que escapan, en gran medida, cuando no totalmente, al control consciente por parte de los agentes humanos. La confrontación con la contingencia y el azar constituye, como a nadie escapa, una de las marcas estructurales de la praxis humana, en sus diversas posibles formas, de modo que la presencia de tales factores se revela, pues, con particular nitidez justamente en aquel 
dominio en el cual la reflexión orientada a fines adquiere un protagonismo central.

Por su parte, en el caso de la naturaleza, no resulta, en modo alguno, incontrovertible que la finalidad tenga o pudiera tener algún papel en ella. De hecho, desde comienzos de la Modernidad, y de modo creciente hasta nuestros días, la posición que asume la presencia de algún tipo de nexo teleológico en la naturaleza se ha visto siempre o casi siempre en la situación de tener que asumir la carga de la prueba. Pero, como quiera que sea que se afirme la presencia de determinado(s) tipo(s) de nexos teleológicos en la naturaleza, lo habitual es que dicha asunción aparezca combinada, de uno u otro modo, con una serie de restricciones destinadas a hacer lugar a la presencia de un rango más o menos amplio de fenómenos que se resisten a ser puestos en conexión, al menos, de modo directo, con consideraciones referidas a lo que serían fines propios de la naturaleza misma. Como lo muestra suficientemente a lo largo de su propia historia la experiencia de la conciencia filosófica, el precio a pagar, allí donde no se está dispuesto a hacer tal tipo de concesiones restrictivas, para persistir obstinadamente en la pretensión de un «teleologismo» o, si se prefiere, un «teleonomismo» integral de carácter burdamente objetivista, no suele ser otro que la lisa y llana reducción al absurdo del propio abordaje teleologista o teleonomista. El veredicto inapelable por medio del cual la conciencia filosófica moderna ha dado cuenta de esta situación frente a los abusos del teleologismo/teleonomismo objetivista, en sus variantes más extremas y también más ingenuas desde el punto de vista metódico, es bien conocido: el pretendido recurso a la explicación por referencia a fines no sería otra cosa, en definitiva, que el asylum ignorantiae, que hace su aparición recién allí donde no se cuenta ya con una genuina explicación, vale decir, con una explicación mecánica para aquello que se pretende explicar en cada caso. La huida hacia dicho refugio no vendría a representar, pues, en último término, sino una consecuencia visible del poder que despliega un pathos no menos conocido: el horror vacui.

Más allá de las peculiaridades que presenta la crítica al teleologismo/teleonomismo practicada por algunos de los más connotados 
filósofos de la Modernidad, el problema que se plantea aquí parece bastante claro, a saber: por un lado, un teleologismo/teleonomismo objetivista de carácter pretendidamente omnicomprensivo se enfrenta con el riesgo de su propia supresión por vía de autorrefutación, más precisamente, con el riesgo de su propia reducción al absurdo; por otro lado, un enfoque teleológico/teleonómico de la naturaleza, que merezca realmente el nombre de tal, no podría renunciar, sin más, a toda pretensión de carácter arquitectónico, sin perder al mismo tiempo su propia razón de ser. Por lo tanto, todo parece indicar que la sostenibilidad de tal tipo de enfoque dependerá en gran medida del éxito con que se afronte, en cada caso, el incómodo desafío de tener que compatibilizar la consideración teleológica/teleonómica con la admisión de la existencia de ámbitos, incluso muy vastos, que parecen quedar reservados al juego de aquello que no puede ser visto más que como contingente o azaroso. Por su parte, el temible rival de todo teleologismo/teleonomismo, esto es, el mecanicismo, incluso el más radical, no presenta los mismos problemas internos, pues su ambición totalizadora podrá verse, tal vez, como una esperanza utópica de imposible realización, al menos, a los ojos de quienes defienden la necesidad del enfoque teleológico/teleonómico, pero no por ello como el reflejo de una ambición conducente, de suyo, a la supresión de aquello mismo que la anima desde su origen. La viabilidad del enfoque teleológico/teleonómico parece tener que ser defendida, pues, en dos frentes diferentes: por un lado, frente a la amenaza de un mecanicismo integral que lo hiciera, sin más, superfluo; por otro, frente a su propia exposición a la posibilidad de autosupresión, allí donde no logre poder dar cuenta satisfactoriamente de su vinculación con la dimensión de la contingencia, la accidentalidad y el azar. En suma, se tiene aquí una situación asimétrica, en la cual no es precisamente el teleologismo/ teleonomismo, sino, más bien, el mecanicismo, la posición que parece contar con una ventaja inicial nada desdeñable, al menos, en el plano puramente argumentativo.

Ya las concepciones de la teleología/teleonomía natural elaboradas en la Antigüedad, al menos, las más refinadas y más influyentes, intentaron hacerse cargo, a su modo, del conjunto de problemas que 
he intentado delinear brevemente en lo anterior. Tal es el caso, por ejemplo, de Platón. Ya desde Fedón y especialmente en Timeo, Platón buscó elaborar una concepción de la teleología/teleonomía natural que pudiera satisfacer dos exigencias fundamentales: por un lado, la necesidad de compatibilizar la reflexión teleológica/teleonómica con la explicación mecánica, tal como Platón la contempla en el desarrollo del modelo compatibilista de explicación causal presentado en Fedón 99b ss.; por otro lado, la necesidad de reconocer la presencia de factores que, lejos de cooperar a la realización de los correspondientes ordenamientos teleológicos/teleonómicos, aparecen más bien, desde el punto de vista que abre la referencia a fines, como factores de interferencia o impedimento, tal como, por ejemplo, la llamada "causa errante" (planōméne aitía), introducida en Timeo 46c ss. Por su parte, Aristóteles prolonga esta línea de consideración, puesto que, en su concepción de la causalidad natural, incorpora tanto el motivo compatibilista de Platón - sobre todo, a través de la concepción relativa a la necesidad hipotética de la materia, desarrollada en Física II 8-, como también la referencia a factores de interferencia o impedimento que, en ocasiones, pueden alterar el curso o el resultado de determinados procesos, tal como éste es esperable en el nivel tipológico de consideración. Habitualmente, Aristóteles se refiere de modo global a estos factores por medio del empleo de cláusulas del tipo ceteris paribus, tales como "si nada lo impide" y otras semejantes, y elabora, de modo complementario, también una concepción positiva de la causalidad accidental destinada, entre otras cosas, a hacer justicia al tipo peculiar de explicación que debe darse en el caso de resultados que no pueden ser reconducidos, sin más, al nivel tipológico de consideración. ${ }^{2}$ Pero, además, en su concepción relativa a las conexiones entre contingencia y finalidad, Aristóteles, da todavía un paso más, que tiene un alcance gigantesco, desde el punto de vista sistemático, pues, al menos, para el caso de la causalidad accidental que pertenece al ámbito de la acción propiamente

2 Para una discusión más amplia del papel que Aristóteles concede a los factores de impedimento en su concepción de la causalidad, en conexión con el empleo de las cláusulas mencionadas, puede consultarse Vigo, 2010. Para una reconstrucción de conjunto de la concepción aristotélica de la causalidad accidental, se puede consultar Rossi, 2011. 
humana, reconoce la dependencia estructural del tipo de contingencia que corresponde a lo que en sentido estricto denomina el «azar» (týche), concebido como un modo peculiar de la causalidad accidental, respecto de la teleología propia del obrar humano: según esto, al menos, en el ámbito de la acción humana, el azar no constituye, a juicio de Aristóteles, el polo opuesto a la teleología, sino, más bien, un caso peculiar de ésta o, si se prefiere, un fenómeno parasitario de la teleología en su significado más básico, que presenta la forma de lo que, siguiendo a Kant, puede llamarse una "teleología como si" (Als-ob-Teleologie). ${ }^{3}$

Pero también en Kant la teleología/teleonomía aparece, por sorprendente que pudiera parecer a primera vista, estructuralmente conectada con la dimensión de la contingencia y el azar, aun cuando, al tematizar dicha conexión estructural, Kant pone la mira en un aspecto diferente del que tiene en vista primariamente Aristóteles. En el caso de Kant se trata, sin embargo, como se verá más abajo, de un modo complementario de articular una misma intuición de base, según la cual es justamente la experiencia del carácter contingente o azaroso de determinados fenómenos la que gatilla, por así decir, cierto tipo de reflexión que posee un carácter irreductiblemente teleológico. Por cierto, no hace falta aclarar que subsiste una diferencia básica e irreductible entre las posiciones de ambos autores, en la medida en que, para Kant, toda forma de explicación teleológica/ teleonómica implica un tipo de consideración que solo resulta posible en el modo del «como si», mientras que, para Aristóteles, solo el «azar» (týche), como forma de la causalidad accidental, posee un carácter parasitario, en el modo del «como si», pero no la teleología/teleolomía de primer orden, vinculada con la causalidad per se, tal como ésta se da en el ámbito de la naturaleza y también de la acción humana. Esta diferencia no es sino el reflejo de superficie de la tesis fundamental de Kant, según la cual el principio del enjuiciamiento teleológico solo puede cumplir una función regulativa, $\mathrm{y}$

3 La caracterización de la concepción aristotélica del azar como una forma de Als-obTeleologie ha sido propuesta originalmente por W. Wieland, en su clásico libro sobre la física aristotélica (1970: p. 254 ss.). 
no una función constitutiva. Pero, por importante que pueda ser en otros respectos, la diferencia señalada no debería impedir reconocer las importantes afinidades estructurales que exhiben las posiciones de ambos autores, allí donde se trata de los aspectos específicamente referidos a la conexión entre contingencia y finalidad.

\section{Contingencia y finalidad en Kant}

Sobre la conexión estructural entre contingencia, en el sentido de lo accidental o azarozo (Zufälligkeit, zufällig) y finalidad, Kant insiste en una considerable cantidad de pasajes de $K U$. Se trata aquí, más precisamente, de un tipo peculiar de accidentalidad/contingencia de origen, que afecta la relación entre el orden natural dado en la experiencia y las capacidades cognoscitivas de nuestro entendimiento. La conexión es enfocada, según los casos, desde uno u otro de dos lados diferentes, a saber: ya desde el lado "subjetivo", ya desde el lado "objetivo", para decirlo por medio de un contraste del que Kant mismo se vale asiduamente. Comento ahora brevemente lo referido a cada uno de esos dos modos de consideración.

a) El lado subjetivo

Para la discusión de este punto, el pasaje más importante se halla en la sección V de la "Introducción" a la obra, que trata del principio de la «conformidad formal a fines de la naturaleza» (Prinzip der formalen Zweckmäßigkeit der Natur), concebido como un principio trascendental de la «facultad del juicio» (Urteilskraft). Dicho principio, explica Kant, es un principio trascendental, y no metafísico, porque apunta a una condición bajo la cual únicamente las cosas pueden llegar a ser objetos de nuestro conocimiento, sobre la base de un concepto empírico ya dado, pero sin poder trasponer a los objetos mismos la regla correspondiente a dicho principio. Así, un principio que admite uso constitutivo, como el principio de causalidad, puede ser interpretado ya en sentido trascendental, cuando se aplica a la idea de un objeto en general, y no a un objeto concreto a través de un concepto 
empírico (vgr. "todo cambio en la determinación de un objeto tiene una causa"), ya en sentido metafísico, cuando se aplica a un objeto determinado a través del correspondiente concepto empírico ( $\mathrm{vgr}$. "todo movimiento de un cuerpo debe tener una causa externa”). En cambio, el principio de la «conformidad formal a fin(es) de la naturaleza», que no posee uso constitutivo, solo admite el primer tipo de interpretación, pero no el segundo ( $K U: \mathbf{x x x})$. Dicho principio adquiere expresión en máximas de la facultad del juicio tales como "la naturaleza sigue el camino más corto" (lex parsimoniae), "la naturaleza no da saltos" (lex continuii in natura), "la naturaleza subsume la multiplicidad diversa bajo pocos principios" (principia praeter neccesitatem non sunt multiplicanda), pero no dice cómo son las cosas en concreto, ni tampoco indica cómo proceden efectivamente nuestros poderes cognitivos a la hora de juzgar, sino que señala tan solo cómo «deben» hacerlo (KU: XXXI). Por lo mismo, vale decir, en virtud de su carácter apriorístico, reclama una deducción de su pretensión de validez. Reconstruida en sus pasos fundamentales, la "deducción” procede como sigue:

i) en los fundamentos de la posibilidad de una experiencia, hay algo necesario, a saber: leyes universales, sin las cuales la naturaleza, en general, no puede ser pensada como objeto de los sentidos. Tales leyes se fundan en categorías, aplicadas a las condiciones formales de la intuición sensible ( $K U: \mathrm{XXXII);}$

ii) bajo dichas leyes, la facultad del juicio tiene un uso meramente determinante, es decir: se limita a subsumir lo dado en la intuición bajo leyes que están dadas de antemano. Así ocurre, por ejemplo, con la aplicación del principio de causalidad: dado el principio del entendimiento (Verstand), se busca la condición de la subsunción de lo dado bajo dicho principio, en este caso, la sucesión de una serie de determinaciones en una y la misma cosa (KU: XXXII);

iii) junto a la determinación formal correspondiente a las leyes del entendimiento -que, desde el punto de vista constitutivo, dan cuenta de lo que en la "Deducción Trascendental" de la segunda edición de Kritik der reinenVernunft $(\mathrm{KrV})$ se denomina la "naturaleza considerada desde el punto de vista de la forma" (natura formaliter spectata) (KrV, DTB $\S 26$, B 165)- hay también otros modos en los que 
son determinados (o determinables) los objetos del conocimiento empírico: además de lo que corresponde a la naturaleza, en general, hay otras «naturalezas» (Naturen), específicamente diferentes entre sí, y cada una de esas especies (Arten) «debe» poseer su regla, la cual es una ley, y como tal, «necesaria», aun cuando nosotros no podamos llegar a «comprender» (einsehen) esa necesidad, pues esta exigencia no es sino una especificación de la exigencia general que plantea el principio de causalidad ( $K U:$ XXXII s.);

iv) por lo tanto, tenemos que pensar en la naturaleza, en lo que concierne a sus leyes empíricas, la posibilidad de una multiplicidad infinita de tales leyes, que resultan, como tales, accidentales/contingentes (zufällig) respecto de nuestra capacidad de conocer, en la medida en que no pueden ser conocidas a priori, por cuanto tampoco tienen su origen en dicha capacidad. Ahora bien, es por referencia a tales leyes como juzgamos la "unidad de la naturaleza" (Natureinheit), según leyes empíricas, y también la posibilidad de la unidad de la experiencia, en tanto «sistema de la experiencia», como una unidad meramente accidental/contingente (zufällig) (KU: XXXII, s.), aunque ello en nada cambia el hecho de que tal unidad debe ser necesariamente supuesta, pues, de lo contrario, no habría algo así como una conexión integral (durchgängiger Zusammenhang) de los conocimientos empíricos, tal que éstos queden vinculados en una totalidad (KU: XXXIII);

v) por consiguiente, la facultad del juicio debe suponer a priori, como el principio que guía su uso, que aquello que aparece como accidental/contingente para la comprensión (Einsicht) humana, en las diversas leyes empíricas de la naturaleza, contiene, sin embargo, una cierta «unidad legal» (gesetzliche Einheit) - que, para nosotros, es insondable (unergründlich), pero, sin embargo, pensable (denkbar)- en el «enlace» (Verbindung) de su diversidad, en una experiencia posible en sí misma (KU: XXXIII);

vi) se sigue que, puesto que la unidad legal presente en tal enlace, que el propio entendimiento exige, no deriva del propio entendimiento, pues se le aparece a éste como accidental/contingente en su origen, debe entonces ser representada como una «conformidad a fin(es)» de los propios objetos de la naturaleza $(K U: \mathrm{XXXIV):} \mathrm{la}$ 
facultad del juicio - que respecto de tales objetos, en tanto correspondientes a determinadas leyes empíricas, opera de modo meramente reflexivo- debe representarse, pues, la naturaleza, en lo concerniente a tales leyes empíricas, según un principio de «conformidad a fin(es)», con referencia a nuestras capacidades de conocer (KU: XXXIV);

vii) tal concepto trascendental de «conformidad a fin(es) de la naturaleza» no es, como tal, ni un «concepto de la naturaleza» (Naturbegriff) ni un «concepto de la libertad» (Freiheitsbegriff), y no puede ser aplicado, por tanto, a ningún objeto de la naturaleza; vale decir: no tiene un ámbito de referencia (Gebiet). Se trata, meramente, del único modo en el cual podemos aproximarnos a una «experiencia integralmente conexa» (durchgängig zusammenhängende Erfahrung), en la reflexión sobre los objetos de la naturaleza. Vale decir: en el caso del mencionado principio de «conformidad a fin(es)» de la naturaleza, se trata de un principio de alcance meramente subjetivo, de una «máxima» de la facultad de juicio, y no de una «ley» de la propia naturaleza $\left(K U:\right.$ XXXIV). ${ }^{4}$

Así elaborada, la «deducción» da cuenta, pues, de la validez a priori, en tanto originada en el modo en el que la facultad del juicio especifica los principios del entendimiento para el caso de las leyes empíricas, de la exigencia de «orden» de la naturaleza en sus leyes específicas o particulares: empíricas. Sin esta presuposición, no se podría pasar de la analogía general de una experiencia posible a su especificación para el caso de las leyes específicas o particulares de dicha experiencia. Pero es el propio entendimiento el que, a través de la instancia de aplicación provista por la facultad del juicio, exige dicho tránsito y reclama el orden de la naturaleza, también según sus leyes empíricas, aun cuando el propio entendimiento nunca podría comprender de antemano dicho orden ni expresarlo de modo exhaustivo, a través de leyes apriorísticas a las que él mismo diera origen $(K U: \mathrm{XXXV})$. Para poder buscar tal orden unitario en la

4 Para la diferencia entre «máximas» (Maxime), como principios subjetivos de determinación, y «leyes» (Gesetze), como principios objetivos de determinación, en el caso concreto de la determinación de la voluntad, puede leerse el primer parágrafo de (Kant, 1990: § 1, pp. 35 ss). 
multiplicidad de las leyes empíricas de la naturaleza, hay que presuponer, pues, un principio apriorístico, a saber: que tales leyes empíricas dan lugar a un «orden reconocible» (erkennbare Ordung) de la naturaleza, al menos, como un orden posible ( $K U: \mathrm{XXXV)}$. Esta «Concordancia» (Zusammenstimmung) de la naturaleza con nuestra capacidad de conocer es algo que la facultad del juicio presupone a priori, como auxilio o guía para la reflexión sobre la naturaleza, en lo que concierne a la multiplicidad de sus leyes empíricas: el entendimiento reconoce tal concordancia, al mismo tiempo, como «objetiva» (objektiv) y, sin embargo, accidental/contingente (zufälig), respecto del propio entendimiento, en la medida en que no tiene su origen en él. La facultad del juicio la atribuye, por tanto, a la naturaleza misma, pero ello solo de modo reflexivo y siempre en relación con la capacidad de conocer propia del sujeto $(K U: \mathrm{XXXVI}) .{ }^{5}$ De este modo, se obtiene un «hilo conductor» (Leitfaden) para la búsqueda de unidad sistemática, en la multiplicidad de las leyes empíricas de la naturaleza. Se sigue, pues, que también la facultad del juicio tiene un principio a priori que le es propio, y que da cuenta de la posibilidad de una naturaleza, pero solo en dirección subjetivo-reflexiva: la facultad del juicio no prescribe dicho principio a la naturaleza (Autonomie), sino, más bien, «a sí misma» (Heautonomie), y ello, más precisamente, con vistas a la reflexión «sobre» la naturaleza. Se trata, más precisamente, de lo que Kant denomina la "ley de especificación de la naturaleza con respecto a sus leyes empíricas” (Gesetz der Spezifikation der Natur

5 Es importante advertir aquí que la referencia a la reflexión está internamente conectada con la referencia a la conciencia del carácter subjetivo del principio empleado. Todo parece indicar que se tiene aquí un caso de «reflexión trascendental», en el sentido específico que Kant asigna a la noción en el tratamiento de la "Anfibología de los conceptos puros de reflexión" en $K r V$ (A 260-268 / B 316-324). En efecto, se trata, en el caso del principio de la facultad del juicio, de una reflexión en la cual la consideración de la correspondencia del concepto comparado con la facultad a la que dicho concepto pertenece originariamente no puede estar ausente. Una cuestión diferente, en la cual no resulta posible entrar aquí, concierne al modo en que debe entenderse la correspondiente exigencia de comparación, según se trate del mero empleo de la reflexión a la hora de indagar la naturaleza o bien de la teoría que tematiza las prestaciones reflexivas que corresponden a la función del juicio teleológico. La misma cuestión se plantea, de modo análogo, también en el caso del tratamiento de los conceptos de reflexión de la «Anfibología». Para una discusión de algunos de estos aspectos, me permito remitir al tratamiento en Vigo, 2006: 27-64. 
in Ansehung ihrer empirischen Gesetze) (KU: XXXVII). A través de tal «ley» ni se prescribe nada a la naturaleza misma, ni se aprende de ella algo por observación, aun cuando la observación confirme la aplicabilidad y la validez de la ley (KU: XXXVIII).

En tal sentido, en la sección inmediatamente siguiente, destinada a establecer la conexión con el sentimiento de placer (sección VI), Kant enfatiza el aspecto vinculado con el papel de la contingencia: la «concordancia» o «adecuación» (Übereinstimmung) de la naturaleza, en la multiplicidad de sus leyes particulares, con nuestra «necesidad» (Bedürfnis) de encontrar para dicha multiplicidad una cierta universalidad en los principios aparece, a la vez (zugleich), como «accidental/contingente» (zufällig) y como «imprescindible» (unentbehrlich) para nuestra «necesidad de comprensión» (Verstandesbedürfnis). Por ello, la «conformidad a fin(es)» de la naturaleza consiste en la concordancia de la naturaleza, en cuanto conforme a fines, con nuestra «intención» (Absicht) dirigida al conocimiento (KU: XXXVIII). Las leyes universales del entendimiento, que a la vez son leyes de la naturaleza, son tan necesarias como las leyes del movimiento de la materia. Pero su producción (Erzeugung) no presupone ninguna intención relativa a nuestra facultad de conocer, sino que simplemente interviene de modo necesario en la constitución de la naturaleza «como objeto» (KU: XXXXVIII-XXXIX). Solo el «orden» (Ordnung) de la naturaleza, en sus leyes particulares, se nos aparece como accidental/ contingente. El hallazgo de tal orden y su principio es, pues, una tarea para el entendimiento, el cual opera con vistas a un «fin» $\left(Z_{w e c k}\right)$ que la facultad del juicio le adscribe a la propia naturaleza, por cuanto el entendimiento mismo no puede aportar aquí ninguna ley que tuviera su origen en él mismo (KU: XXXIX).

b) El lado objetivo

Ahora bien, lo comentado hasta aquí concierne tan solo a uno de los dos aspectos que Kant pone de relieve, cuando se trata de la conexión entre contingencia y finalidad, a saber: la accidentalidad/ contingencia del orden de la naturaleza, en sus leyes particulares 
(empíricas), «respecto de la función constitutiva del entendimiento». Se trata, por tanto, de lo que he llamado el lado «subjetivo» del problema. El segundo aspecto, igualmente importante, concierne al lado «objetivo» de la cuestión. Se trata, en este caso, del hecho de que la consideración teleológica de los objetos naturales, más precisamente, de aquellos que pueden ser vistos como «productos de la naturaleza»y, a la vez, como sus «fines» (Naturzwecke), trae necesariamente consigo un modo peculiar de consideración de lo que naturaleza tiene de mero mecanismo. Tal modo de consideración pone de relieve lo que sería la esencial accidentalidad/contingencia de lo que aparece como mero producto del mecanismo natural. Kant pone de relieve este segundo aspecto en el comienzo mismo de su tratamiento de la «conformidad a fin(es)» objetiva (objektive Zweckmäßigkeit) de la naturaleza, más precisamente, en los parágrafos 61-63 de KU.

En el § 61, dedicado a introducir la noción misma de la «conformidad a fin(es)» objetiva de la naturaleza, Kant explica que este tipo de «conformidad a fin(es)» debe distinguirse nítidamente de aquella otra, de carácter puramente subjetivo, tratada en la primera parte de $K U$, que concierne a la relación de las formas (bellas) de la naturaleza con nuestras facultades cognitivas. En efecto, la situación es ahora completamente diferente, ya que no se trata de la relación que dichas formas naturales mantienen con nuestras facultades de conocer, sino, más bien, de las relaciones que mantienen ellas mismas, cada una en su propia constitución interna y también entre sí ( $K U$ : 267 s.). Kant explica, en este sentido, que la «conformidad a fin(es)» objetiva, considerada como principio de la posibilidad de las cosas de la naturaleza, está muy lejos de mantener una conexión necesaria (notwendig) con el propio concepto de naturaleza. Dicho de otro modo: a la «conformidad a fin(es)» de carácter objetivo se apela, sobre todo, allí donde se pretende probar a partir de ella precisamente la accidentalidad/contingencia (Zufälligkeit) de la naturaleza y su forma, tal como ésta se da de modo efectivo, vale decir, de un modo que hubiera podido ser también de otra manera. Así, por ejemplo, cuando se explica el modo en el cual está constituida la anatomía de un ave y se indica, por caso, que el largo sus de alas se adapta a tal o cual función, se está asumiendo a la vez que, según la mera conexión 
de causas eficientes (nexus effectivus) dada en la naturaleza, es decir, sin considerar la peculiar forma de enlace que corresponde al nexo de finalidad (nexus finalis), todo lo así constituido resulta accidental/ contingente (zufällig), en el más alto grado. En efecto, considerada como mero mecanismo, la naturaleza se podría haber configurado de otros incontables posibles modos. En el mero mecanismo natural no podría encontrarse, pues, ninguna razón para introducir un principio como el que corresponde al nexo de finalidad ( $K U: 268 \mathrm{~s}$.).

Ahora bien, lo anterior no impide en modo alguno, explica Kant, que el enjuiciamiento teleológico (die teleologische Beurteilung) pueda ser empleado con derecho (mit Recht) en la investigación de la naturaleza, al menos, a título problemático (problematisch), vale decir, hipotético, pero ello tan solo en razón de la analogía con la causalidad según fines (nach der Analogie mit der Kausalität nach Zwecken), y al solo efecto de poner la investigación de la naturaleza bajo principios de la observación y la indagación (unter Prinzipien der Beobachtung und Nachforschung), vale decir, sin la pretensión de explicar (erklären) la naturaleza de ese modo. El enjuiciamiento teleológico pertenece, pues, a la función reflexiva de la facultad del juicio, y no a su función determinante (KU: 269). El concepto de enlaces y formas naturales que responden a ciertos fines (nach $Z$ wecken) proporciona, al menos, un principio adicional (mehr), que permite poner los fenómenos naturales bajo reglas (unter Regeln), allí donde las leyes de la causalidad de carácter puramente mecánico ya no resultan suficientes. En efecto, introducimos un fundamento teleológico (teleologischer Grund) allí donde a un cierto concepto del objeto, considerado «como si» (als $o b$ ) estuviera dado en la naturaleza, y no en nosotros mismos, le atribuimos causalidad respecto del correspondiente objeto, o bien allí donde nos representamos la posibilidad del objeto según la analogía con una causalidad como la que encontramos en nosotros mismos, y pensamos entonces la naturaleza "como (si fuera) algo de carácter técnico" (als technisch), en virtud de su propia capacidad (durch eigenes Vermögen) (KU: 269 s.).

Obviamente, el principio empleado en tal modo de proceder posee, a juicio de Kant, un alcance puramente regulativo (ein regulatives Prinzip), pues se emplea para el mero enjuiciamiento (für die 
bloße Beurteilung) de los fenómenos. Tal uso no implica una genuina atribución a la naturaleza de causas que operan de modo intencionado (absichtlich wirkende Ursachen), esto es, de genuina «teleología» (Teleologie), en el sentido estricto de la expresión que supone la mediación de un cierto logos referido al telos. Si, en cambio, se pretendiera darle a dicho principio de enjuiciamiento el carácter de un principio constitutivo que da cuenta de la derivación (Ableitung) de los correspondientes productos (Produkte), a partir de las correspondientes causas, entonces el concepto de «fin de la naturaleza» (Naturzweck) pertenecería a la función determinante de la facultad del juicio, y no a la función reflexiva (KU: 270). Pero, entonces, dicho principio no pertenecería propiamente a la facultad del juicio, ya que, en su función determinante, ésta toma el principio que debe aplicar de otras facultades. Más precisamente, se trataría, en tal caso, de un concepto de la razón (Vernunftbegriff), que introduciría un nuevo tipo de causalidad en la ciencia de la naturaleza: un nuevo tipo de causalidad que tomaríamos de nosotros mismos y que aplicaríamos, sin embargo, a seres diferentes de nosotros mismos, sin poder suponer que éstos tienen el mismo modo de ser (gleichartig) que nosotros (KU: 270). Como es obvio, esto último es imposible. ${ }^{6}$

6 Es importante hacer notar que incluso en el caso de la «conformidad a fin(es)» objetiva de tipo puramente formal, tal como se da en el ámbito de los objetos matemáticos, Kant pone de relieve el papel que desempeña el componente de la accidentalidad/ contingencia que pone de manifiesto lo producido, aunque se trate aquí de objetos construidos según reglas del entendimiento. En este caso, el factor de sorpresa e inagotabilidad, por así decir, se vincula con el papel que Kant asigna a la intuición pura en la construcción de los conceptos. En efecto, en la discusión llevada a cabo en el § 62 de $K U$, Kant explica que la «conformidad a fin(es)» de carácter objetivo, pero meramente formal, motiva con razón nuestra admiración, a pesar de no poseer ella misma un carácter real. Ello se explica por el peculiar carácter de productividad que muestran las correspondientes reglas conceptuales, allí donde se aplican a la determinación de la intuición pura. Puesto que la construcción matemática no es un procedimiento a través de meros conceptos, sino que involucra la forma de la intuición, de modo tal que posee carácter sintético, y no meramente analítico, se comprende que pueda dar lugar a un peculiar tipo de experiencia de accidentalidad/contingencia: la concordancia (Übereinstimmung) del objeto con la necesidad (Bedürfnis) de reglas que es propia del entendimiento aparece, en sí misma (an sich), como accidental/contingente (zufällig), respecto del propio entendimiento, y, por lo mismo, como posible tan solo en razón de la referencia a un correspondiente fin ( $K U: 275$ s.). Ahora bien, esto indicaría que el caso de los objetos matemáticos es diferente, en este punto, del caso del esquematismo de 
Enjuiciamiento teleológico y fines de la naturaleza

Paso ahora al segundo de los puntos mencionados al comienzo, a saber: el referido a la estructura, la función y el alcance que Kant asigna al enjuiciamiento teleológico, allí donde se trata de dar cuenta de la posibilidad y la presencia de «fin(es) natural(es)»o «fin(es) de la naturaleza» (Naturzweck $(e)$ ). Para el tratamiento de este punto, hay que acudir a la discusión que Kant elabora en los parágrafos 64-66 de $K U$, donde el caso focal en el que se centra la consideración de los «fines de la naturaleza» viene dado, como se sabe, por los «organismos», o bien «seres organizados» (organisierteWesen), como los llama Kant. ${ }^{7}$ Paso revista brevemente a los aspectos centrales del tratamiento que Kant lleva a cabo.

a) Los requerimientos del empleo de la noción de «fin(es) de la naturaleza» $(K U: \S 64)$

La existencia de «seres organizados» provee el fundamento empírico de la necesidad de recurrir al peculiar tipo de consideración y enjuiciamiento en el que se basa el modo de hablar que hace referencia a «fines de la naturaleza». La legitimidad de dicho modo de consideración tiene, según Kant, requerimientos iniciales que no pueden ser pasados por alto. En efecto, para reconocer que una cosa solo puede ser posible como «fin de la naturaleza» - es decir, para reconocer que la causalidad de su origen (Ursprung)-, hay que buscarla no en el mecanismo de la naturaleza, sino, más bien, en su capacidad de operar por medio

los conceptos puros del entendimiento, pues en este caso tenemos solo una aplicación cuasi-mecánica de unas pocas reglas conceptuales a la intuición pura del tiempo, y no una inmensa variedad de reglas generables espontáneamente que, luego, encuentran la confirmación de su constructibilidad en su aplicación a la intuición pura. Tal diferencia explica por qué, en el ámbito matemático, hay, por así decir, ocasión de hacer experiencia de descubrimiento. El tipo de admiración que se produce aquí tiene que ver, pues, con la reiterada experiencia de la concordancia y la compatibilidad de entendimiento e intuición, experimentada como tal, una y otra vez, con ocasión de la lograda construcción/exhibición del correspondiente concepto en la intuición pura (1973: 277).

7 La palabra «organismo», propia de la biología del siglo XVII, no es empleada por Kant, que habla, en cambio, de «ser(es) organizado(s)» (organiserte(s) Wesen). 
de conceptos. Se requiere que su forma no sea posible según meras leyes naturales -vale decir: aquellas según leyes que pueden ser aplicadas a los fenómenos de los sentidos por medio del entendimiento-, sino, más bien, que incluso su conocimiento empírico, según causa y efecto, presuponga ya conceptos de la razón ( $K U: 284 \mathrm{~s}$.).

Ahora bien, explica Kant, hay en todas las leyes empíricas una accidentalidad/contingencia (Zufälligkeit) de la forma del objeto correspondiente respecto de la propia razón. En efecto, la razón debe (re)conocer la necesidad (Notwendigkeit) en la forma de un producto de la naturaleza, cualquiera sea dicha forma, si ha de poder comprender las condiciones conectadas con su producción. Pero, en el caso de las leyes empíricas, la razón, como se vio, no puede suponer dicha necesidad en una forma cualquiera dada. Sin embargo, justamente esta accidentalidad/contingencia con relación a la razón provee ya ella misma un motivo o fundamento (Grund) para asumir la causalidad del correspondiente objeto «como si» (als ob) ella fuera posible solo a través de la razón. En este caso, la razón es la facultad de obrar según fines (voluntad), y el objeto, que solo puede representarse como posible a partir de dicha facultad, solo podría ser representado como posible en calidad de fin (als $Z_{w e c k}$ ) (KU: 285). Así ocurre, por ejemplo, en el caso de los productos del arte: un círculo trazado en la nieve se representa como fin, pero no como fin de la naturaleza, sino como producto del arte, y como vestigio del obrar humano (vestigium hominis video) (KU: $285 \mathrm{~s}$.). En el caso de los productos de la naturaleza, para poder considerarlos, a la vez, como «fines de la naturaleza», se requiere más, a saber: una cosa existe como fin de la naturaleza, cuando ella misma constituye, a la vez, su propia causa y su propio efecto, tomadas las expresiones «causa» $\mathrm{y}$ «efecto», en cada caso, en un sentido diferente. Aquí se introduce una forma peculiar de causalidad que no puede ser conectada con el mero concepto de naturaleza, sin presuponer en ella la referencia a un cierto fin, pero que, una vez introducida dicha referencia, puede ser pensada (gedacht) sin contradicción, aun cuando no pueda ser propiamente conocida por medio de conceptos (begriffen) (p. 286). Lo que Kant tiene en vista aquí es el carácter auto-productivo de los seres vivientes organizados, que son los únicos genuinos «fines 
de la naturaleza». ${ }^{8}$ Así, por ejemplo, un árbol, se "produce o genera (erzeugen) a sí mismo" en tres sentidos diferentes, a saber: i) según la especie, un árbol genera un árbol de la misma especie; ii) según el individuo, un árbol se genera o produce a sí mismo, en cuanto es capaz de crecimiento, un fenómeno especialísimo del ámbito de la vida, para el cual no hay nada ni de lejos parecido en ningún arte; y iii) según sus partes, cada parte del ser viviente organizado se genera a sí misma de tal modo que la conservación de una parte depende recíprocamente de la conservación de otra (KU: 286-288).

b) Mecanismo y teleología: el modelo causal compatibilista (KU: § 65)

La consideración del organismo como «fin de la naturaleza» en el $\S 65$ apunta a precisar el peculiar modelo de causalidad anticipado en el parágrafo anterior, a saber: una causalidad en razón de la cual la misma cosa es causa y efecto de sí misma, aunque en un sentido diferente de la expresión en cada caso. Para ello, Kant comienza por establecer una distinción entre i) causalidad eficiente y ii) causalidad final. En primer lugar, i) el enlace causal (Kausalverbindung), tal como lo establece el entendimiento, es un enlace que constituye una serie de causas y efectos de carácter esencialmente retrospectivo, en la medida en que va siempre del efecto a la causa, de modo tal que, en la serie así constituida, nada que sea efecto de una cosa puede ser, a la vez, causa de esa misma cosa. ${ }^{9}$ Este tipo de enlace causal es el que

8 Para el contexto histórico del tratamiento kantiano del organismo, puede verse la buena discusión en (McLaughlin, 1989: cap. 1). McLaughlin presenta el modo en el que Kant recibe la teoría biológica del organismo, tal como se había desarrollado hacia 1750, y la teoría biológica del siglo XVIII, y discute también el fracaso de la teoría mecanicista, basada en el concepto de "preformación", que pretendía explicar el desarrollo de los organismos vivientes a partir de la disposición de sus partes, tal como ocurre en el caso del movimiento de una máquina como un reloj (y para el desarrollo de esta misma idea en Descartes: Des Chene, 2001: caps. 4-6). McLaughlin considera también el asíllamado «newtonianismo biológico», que Kant, como se sabe, rechaza.

9 No se considera aquí el caso de la «acción recíproca» o «comunidad», en el cual se enlazan causalmente dos sustancias a través de sus respectivos estados, de tal modo que una es causa del estado de la otra, y viceversa. Sin embargo, esto no constituye excepción a lo dicho sobre el carácter irreversible del nexo causal de eficiencia, pues se trata, en estos casos, de sustancias y estados diferentes. 
se llama el «enlace de las causas eficientes» (Verbindung der wirkenden Ursachen, nexus effectivus). En cambio, ii) se puede pensar un enlace causal según un concepto de la razón (nach einem Vernunftbegriff) referido a fines (von $Z$ wecken), de modo tal que la correspondiente serie de causas y efectos envuelve relaciones de dependencia que van en las dos direcciones, por así decir, de arriba abajo y de abajo arriba: la cosa que es considerada como efecto, aparece, considerada en la otra dirección, como causa de aquello de lo cual ella misma es efecto. Dicho de otro modo: la serie correspondiente al nexo de causalidad final representa la inversión de la serie que presenta el correspondiente nexo de causalidad eficiente, pues lo que en el nexo de causalidad eficiente aparece como efecto es considerado, a la vez, como causa de aquello mismo que lo produce, cuando es considerado como fin. Como explica Kant, en el dominio del arte es muy fácil encontrar este tipo de enlace, por caso: la casa es, en un sentido amplio que remite al nexo de causalidad eficiente, la causa del dinero que se obtiene de ella al darla en alquiler, pero el dinero a obtener muy bien puede haber sido, a su vez, la causa de la construcción de la casa, en el sentido que corresponde al nexo de causalidad final ( $K U$ : 289 s.). Kant sugiere que una denominación alternativa para ambos tipos de causalidad sería i) el enlace de las «causas reales» (reale Ursachen) y ii) el enlace de las «causas ideales» (ideale Ursachen), y señala que éstas son las dos únicas posibles formas de causalidad con las que es posible contar (KU: 290).

Formulado en los términos de la anterior distinción, el problema sistemático a abordar es, pues, el de cómo puede aplicarse la «causalidad final/ideal» en la naturaleza, que es, en principio, el dominio de la «causalidad eficiente/real», y que es, además, algo a lo cual no puede atribuírsele propósito consciente, lo que marca un límite interno de toda posible analogía con el caso del arte. En este respecto, la primera pregunta es la de cómo puede ser algo considerado, en general, como un «fin de la naturaleza». Ante todo, se exige aquí que las partes de la cosa, tanto en su existencia como según su forma, solo sean posibles en virtud de su relación con el todo. Que la cosa es un «fin» significa que queda comprendida bajo un concepto o una idea (Idee), que determina a priori todo lo que 
debe estar contenido en ella. Ahora bien, en la medida en que una cosa sea pensada como posible solo de ese modo, constituye meramente una obra o producto del arte (Kunstwerk): un producto de una causa racional diferente de la propia materia de la cosa, una causa inteligente que, en la producción y la conexión de las partes de la cosa, es determinada por la idea que ella misma posee de un posible todo que surge en virtud de tal conexión de partes. Tal todo no es, pues, causado por una naturaleza exterior a él mismo (KU: 290). En cambio, para que la cosa, vista como un producto de la naturaleza, contenga en sí una referencia a fines, vale decir, para que sea posible solo como «fin de la naturaleza» y sin referencia a la causalidad de los conceptos perteneciente a seres racionales diferentes de ella, se exige «además» que las partes de la cosa se vinculen en la unidad del todo de modo tal que ellas mismas sean recíprocamente causa y efecto de su propia forma. En efecto, ésta es la única manera de que la idea del todo determine la forma y el enlace de todas las partes, a saber: no como causa, pues entonces la cosa sería un producto del arte, sino como «fundamento del conocimiento» (Erkenntnisgrund) de la unidad sistemática de la forma y el enlace de toda la multiplicidad contenida en la materia, para aquel que somete a enjuiciamiento dicha totalidad (KU: 290 s.). Para que un cuerpo pueda ser enjuiciado en sí y en su posibilidad interna como un «fin de la naturaleza», se exige, pues, que todas sus partes, tanto en su forma como en su enlace, se produzcan de modo recíproco a partir de su propia causalidad, y den lugar así una totalidad, cuyo concepto, a su vez, pueda ser considerado, en un ser que poseyera el tipo de causalidad por conceptos apropiado para dar lugar a tal producto, como causa de esa misma totalidad, según un determinado principio. Por tanto, el enlace de las causas eficientes debe poder ser enjuiciado aquí, al mismo tiempo (zugleich), como un efecto obtenido por medio de causas finales (Wirkung durch Endursachen) (KU: 291).

En un producto de la naturaleza que posee tal índole, cada parte debe ser pensada como existente «con vistas» (um... willen) a las otras, esto es, como «órgano». Para ello, no bastaría que cada parte fuera un mero instrumento del arte, sino que debe ser ella misma un órgano «productor» (hervorbringendes Organ) de las otras partes. Algo 
así solo puede ser un producto de la naturaleza, que provee la materia para todos los instrumentos del arte, y no uno de tales instrumentos. Solo un producto natural de tal índole, en tanto ser organizado que se organiza a sí mismo (als organisiertes und sich selbst organisierendes Wesen), puede ser denominado un «fin de la naturaleza» (Naturzweck) (KU: 292 s.). En un artefacto, por caso, un reloj, las partes no se autoproducen ni se producen recíprocamente, de modo tal que la causa productora no reside en el propio artefacto, sino en un ser inteligente diferente de él. Un «ser organizado» no es, pues, una mera máquina, pues posee no solo fuerza motora (bewegende Kraft), sino también fuerza formadora o configuradora (bildende Kraft), que es capaz de comunicar incluso a materiales que por sí mismos no la poseen, tal como ocurre en el proceso de la reproducción. Nada de esto puede ser explicado en términos de mero mecanismo $(K U: 293) .{ }^{10}$

10 Respecto de la analogía entre el arte y la naturaleza, Kant explica que se queda siempre muy corta, pues el artista se piensa como algo exterior a la naturaleza misma. De este modo, no se hace debida justicia al aspecto de autoorganización que caracteriza a la producción de las formas naturales, su distinción en especies, sus diferenciaciones con vistas a la conservación, etc. Más ajustada es la comparación de esta "propiedad insondable" (unergründliche Eigenschaft) con el fenómeno de la vida, pero esta comparación también entraña peligros, pues o bien se anima la materia al modo del hilozoísmo, o bien se le atribuye un principio que la acompaña y da cuenta de su actividad (un alma) y, en este último caso, o bien se presupone ya la propia organización de la materia, que cumple entonces la función de instrumento del alma, o bien se piensa el alma misma como una especie de artesano, de modo tal que el producto ya no le pertenece a la propia naturaleza, aunque forme parte de ella. En rigor, la organización de la naturaleza no tiene genuino análogo en ninguna otra forma conocida de causalidad, y tal vez la única analogía un poco más aceptable, dentro de sus claros límites, es la que se deriva del empleo de la noción de organización en el ámbito de las instituciones políticas (KU:. 293 s.). En su importante libro The Genesis of Kant's Critique of Judgement (1992) Zammito ha mostrado la importancia de la confrontación con las tesis del Sturm und Drang y con los debates en torno al panteísmo, vinculados con el giro romántico del pensamiento, cuando se trata de explicar el giro que experimenta el pensamiento de Kant en $K U$. Según Zammito, al elaborar la concepción de $K U$, Kant no solo está preocupado de clausurar su propio programa crítico, sino, a la vez, también de tomar posición en los debates que dominan su época. Zammito muestra, en particular, que la rivalidad con Herder, defensor de un inaceptable «hilozoísmo panteísta», y la adhesión a las ideas cristianas tradicionales relativas a Dios y la libertad humana, juegan un papel decisivo para explicar el modo en el que Kant intenta situarse por medio de la concepción elaborada en $\mathrm{KU}$ : la continuación del programa de la Aufklärung termina aquí por confluir con una defensa de la concepción cristiana tradicional, frente al desafío planteado por las tendencias panteístas del romanticismo, que, en cierto modo, 
c) Caracterización del «ser organizado» como «fin de la naturaleza» $(K U: \S 66)$

De acuerdo con lo establecido, la definición del principio de enjuiciamiento de la «conformidad a fin(es)» de carácter objetivo e interno, tal como ésta se da en los «seres organizados», establece que "un producto organizado de la naturaleza es aquel en el cual todo es fin y recíprocamente también medio", de modo tal que nada es aquí «en vano» (umsonst) o «carente de fin» (zwecklos) o meramente atribuible al ciego mecanismo de la naturaleza (KU: 295 s.). La ocasión (Veranlassung) para la derivación de este principio la provee la experiencia; más precisamente, aquel tipo de experiencia que se lleva a cabo de modo metódico, es decir, la observación (Beobachtung) de la naturaleza. Sin embargo, la universalidad y la necesidad que el principio atribuye a tal forma de la «conformidad a fin(es)» no puede apoyarse en meros fundamentos empíricos, sino que debe tener en su base un principio a priori, aun cuando éste posea un alcance meramente regulativo, y aun cuando los correspondientes fines estuvieran en la idea del que lleva a cabo el enjuiciamiento, y no en una causa operante determinada. En tal sentido, puede decirse, explica Kant, que el mencionado principio constituye una «máxima de enjuiciamiento» (Maxime der Beurteilung) de la «conformidad a fin(es)» de carácter objetivo e interno, que es propia de los «seres organizados» (KU: 296). Es en el enjuiciamiento de los «seres organizados» y sus partes donde encuentra, pues, su genuino ámbito de aplicación la máxima tradicional de la filosofía natural según la cual la naturaleza no hace nada en vano (KU: $296 \mathrm{~s}$.).

El concepto de un «fin de la naturaleza», empleado como hilo conductor en el enjuiciamiento de los seres organizados, conduce a la razón a un orden de cosas totalmente diferente del que corresponde al mero mecanismo de la naturaleza, el cual, en este preciso contexto explicativo, ya no resulta, como tal, suficiente. En la base

pueden verse como una recaída en el spinozismo. En este sentido, piénsese en el papel que el pensamiento de Spinoza jugará nuevamente en el caso de autores como Fichte y Hegel. 
de la posibilidad del producto de la naturaleza hay que colocar, pues, una idea. Ésta constituye una «unidad absoluta» (absolute Einheit) de la representación, mientras que la materia representa una multiplicidad de cosas que, por sí misma, no puede proveer ninguna unidad de composición (Einheit der Zusammensetzung). Por tanto, si la unidad de la idea ha de servir incluso como fundamento apriorístico de determinación de una ley natural de la causalidad que pertenece a la forma respecto del compuesto, se sigue entonces que el «fin de la naturaleza» debe ser extendido a todo aquello que está contenido en su producto. En efecto, una vez que hemos referido tal efecto, en su totalidad, a un fundamento de determinación suprasensible, yendo más allá del ciego mecanismo de la naturaleza, debemos enjuiciar a ésta, en todo sentido, de acuerdo con dicho principio. Y no hay ninguna razón para hacer a la forma de la cosa dependiente de ella, siquiera parcialmente, pues entonces la mezcolanza de principios resultante no proveería ya ninguna regla segura de enjuiciamiento (keine sichere Regel der Beurteilung) (KU: 297). Así, por caso, siempre será posible que determinadas partes de un cuerpo animal (vgr. piel, huesos, pelos) puedan ser concebidas como resultantes de meras leyes mecánicas. Pero la causa que provee la materia adecuada para ellas, que las modifica, les da forma y las coloca en el lugar apropiado, debe ser enjuiciada siempre en términos teleológicos. Por lo mismo, en el cuerpo del animal, todo debe ser considerado como organizado, y todo es también órgano, al menos, en cierta relación respecto de la cosa (KU: 298).

d) El enjuiciamiento de la naturaleza como «sistema de fines» $(K U: \S 67)$

Ahora bien, a diferencia de lo que ocurre en el caso de la «conformidad a fin(es)» de carácter interno, en el caso de la «conformidad a fin(es)» de carácter meramente exterior, no hay suficiente derecho (keine hinreichende Berechtigung) para valerse de las cosas naturales, al mismo tiempo, como «fines de la naturaleza», que proveyeran fundamentos de la explicación (Erklärungsgründe) de su propia existencia, ni tampoco para valerse de aquellos de sus efectos que resulten, 
de modo accidental/contingente (zufällig), «conformes a fines»en la idea (in der Idee), como fundamentos de la existencia de esos objetos, según el principio de las causas finales. Vale decir: en aquellas cosas de las cuales no se tiene razón para considerar a ninguna de ellas, por sí misma, como un fin, las relaciones exteriores que mantienen entre sí solo pueden considerarse «conforme a fin(es)», a título meramente hipotético (KU: 298 s.).

En efecto, es diferente enjuiciar una cosa como «fin de la naturaleza» en razón de su forma interna, por un lado, y considerar la existencia misma de esa cosa como un «fin de la naturaleza», por el otro. Para lo segundo, no solo se necesita el concepto de un posible fin, sino también el conocimiento del «fin final» (Endzweck, scopus) de la naturaleza misma. Esto reclama una referencia de la naturaleza a algo suprasensible, lo cual sobrepasa por mucho todo nuestro conocimiento teleológico de la naturaleza: el fin de la naturaleza, como un todo, debe ser buscado más allá de la propia naturaleza (KU: 299). Por ello, cuando dejamos atrás el enjuiciamiento de algo como «fin de la naturaleza» según su forma (vgr. el pasto) y pasamos a la consideración de las diversas relaciones de «conformidad a fin(es)» de carácter externo en las que puede quedar incluido ( $\mathrm{vgr}$. su utilidad como alimento del caballo, el cual sirve, a su vez, para que el hombre haga tal o cual cosa, etc.), solo podemos llegar a fines hipotéticos, no categóricos. En efecto, toda relación de «conformidad a fin(es)» se funda siempre, en estos casos, en alguna otra condición adicional, y la cadena entera de condiciones no puede cerrarse, a menos, que se dé con algo cuya existencia aparezca como incondicionada, vale decir, a menos que se halle algo que existiera como un «fin final» (Endzweck). Pero algo así tiene que estar situado, como tal, fuera del ámbito que abarca la consideración físico-teleológica del mundo. Por lo mismo, tal cosa no puede ser un «fin de la naturaleza», en el sentido más estrecho del término, pues esa misma cosa (o su especie) no podría ser considerada ya como un producto de la propia naturaleza $(K U: 300)$.

Atendiendo a esto último, hay que decir, pues, que solo la materia, en la medida en que se presenta como organizada, trae consigo la necesidad de concebirla como un «fin de la naturaleza», y ello 
justamente porque su forma específica, en cada una de sus diferentes configuraciones organizadas, constituye ella misma, a la vez, un producto de la propia naturaleza. Ahora bien, este mismo concepto de «fin de la naturaleza» conduce necesariamente a la idea de la naturaleza entera como un "sistema constituido de acuerdo con la regla de los fines” (ein System nach der Regel der Zwecke), y a dicha idea debe quedar subordinado todo mecanismo de la naturaleza según principios de la razón, cuando menos, a los fines de la indagación de los fenómenos naturales. Sin embargo, con respecto a la naturaleza misma, el principio de la razón solo tiene validez en calidad de principio subjetivo, vale decir, como una máxima que permite orientar la indagación, a saber: "todo en el mundo es bueno para alguna cosa, nada en el mundo es en vano”. En virtud del ejemplo que provee la naturaleza con sus productos organizados, se está habilitado (berechtigt), e incluso llamado (berufen), explica Kant, a no esperar de ella y sus leyes nada que no sea, en general (im ganzen), «conforme a fin(es)» (KU: 300 s.). Obviamente, no se trata en este caso de un principio para el uso determinante de la facultad del juicio, sino solo para su uso reflexivo. El uso de tal principio es, pues, meramente regulativo, y no constitutivo: por medio de él solo obtenemos un «hilo conductor» (Leitfaden) para considerar las cosas naturales con arreglo a un nuevo ordenamiento legal, y por referencia a un fundamento de determinación ya dado. De este modo, podemos ampliar el estudio de la naturaleza (Naturkunde) según un nuevo principio, el de las causas finales, pero dejando intacto (unbeschadet) el principio del mecanismo de la causalidad natural. Además, de esta forma no se decide todavía la cuestión de si alguna cosa que enjuiciamos según ese principio es o no «intencionalmente» (absichtlich) un «fin de la naturaleza»; por caso, la cuestión de si el pasto «existe» para el caballo o el buey o la oveja, o si esas y todas las demás cosas «existen» para el ser humano (KU: 301). Por último, también la belleza de la naturaleza, es decir, su concordancia (Zusammenstimmung) con el juego libre de nuestras facultades cognitivas, en la aprehensión y el enjuiciamiento de su manifestación fenoménica, puede ser considerada en el modo de la «conformidad a fin(es)» objetiva externa de la naturaleza en su conjunto, vista como un sistema del cual el ser 
humano mismo es un miembro. Esto resulta posible, una vez que el enjuiciamiento teleológico de la naturaleza, a través de los fines de la naturaleza provistos por los seres organizados, nos ha dado ya derecho a valernos de la idea de un gran sistema de fines de la naturaleza. Sobre esta base, podemos considerar como un «favor»o una «dádiva» (Gunst) de la naturaleza para con nosotros el hecho de que, además de lo que es útil, distribuya tan abundantemente belleza y estímulos (Reize), y podemos amarla por ello, a la vez que la consideramos con respeto, por causa de su inmensidad, y nos sentimos nosotros mismos ennoblecidos (veredelt) en tal contemplación: todo se presenta ante nosotros como si ( $a l s o b$ ) la naturaleza hubiera instalado y adornado su grandioso escenario, precisamente, con esa misma intención (eigentlich in dieser Absicht) (KU: $303 \mathrm{~s}$.).

En suma: en la naturaleza descubrimos una capacidad (Vermögen) de producir (hervorbringen) productos que solo podemos pensar por medio del concepto de causa final. Pero, una vez descubierta dicha capacidad, nos vemos impulsados necesariamente a ir más allá y consideramos como pertenecientes a un sistema integral de fines incluso aquellos fenómenos que, tomados por sí mismos, no reclamarían otra explicación que la que puede darse en términos del mero mecanismo ciego de la naturaleza. Y, dado que la primera idea, en lo que toca a su fundamento, ya nos conduce más allá del ámbito de lo sensible, ocurre entonces que la unidad del principio suprasensible exige que se lo aplique no solo a ciertas especies de seres naturales, sino que se lo extienda también a la naturaleza como un todo, considerada como sistema ( $K U: 304)$. Dicho de otro modo: el mismo tipo de extensión del enjuiciamiento teleológico que se hacía necesario en la consideración del organismo particular, en virtud de la cual todas sus partes quedaban comprendidas en el enjuiciamiento teleológico, tiene lugar también en el plano correspondiente a la consideración de la naturaleza como un todo, y por los mismos motivos. La unidad del principio suprasensible que pone en juego tal tipo de enjuiciamiento no admite más que una aplicación integral a todo cuando forma parte de la totalidad que puede ser comprendida por referencia a dicho principio. 
e) Excurso: el alcance «hermenéutico» de la concepción kantiana

Para concluir con esta parte del tratamiento, quisiera llamar brevemente la atención sobre la conexión que vincula, en el empleo kantiano, la noción de enjuiciamiento teleológico, por un lado, y el vocabulario de la comprensión, por el otro. En el tratamiento del principio de la «conformidad a fin(es)» de la naturaleza de $K U$, Kant se vale en ocasiones de expresiones tales como «conocimiento» (Erkenntnis) y «fundamento de conocimiento» (Erkenntnisgrund). Sin embargo, la noción de conocimiento no está empleada en tales casos en el sentido más propio y más estrecho, tal como es tematizado y reconstruido en el marco de la teoría de la constitución de la experiencia presentada en $\mathrm{KrV}$. De hecho, buena parte del esfuerzo de Kant en el tratamiento de la reflexión y el enjuiciamiento teleológico en $K U$ está dirigida, precisamente, a enfatizar el hecho de que el principio de «conformidad a fin(es)» de la naturaleza no puede ser objeto de un uso constitutivo, sino que posee siempre un uso meramente heurístico y regulativo. Con todo, el empleo ampliado de la noción de conocimiento, en un contexto en el cual justamente lo que se tiene en vista no son prestaciones cognoscitivas, en el sentido más propio del término, no puede sorprender demasiado, si se tiene en cuenta que también en otros casos Kant se vale de la noción de conocimiento en un sentido amplio, que no trae consigo las exigencias que establece la concepción elaborada en $\mathrm{KrV}$. Piénsese, en este sentido, en el empleo de la noción de «conocimiento práctico» (praktische Erkenntnis) en el marco del tratamiento de la determinación apriorística de la voluntad (Wille) por la razón (pura) práctica (praktische Vernunft), tal como se lleva a cabo en Kritik der praktischen Vernunft (por ejemplo: $K p V \S 1$ Anm.: 36). ${ }^{11}$

Ahora bien, aunque no se trata ni podría tratarse de lo que Kant llama conocimiento, en sentido estricto, no menos cierto es que el peculiar modo de acceso a los «fines de la naturaleza» que facilita la reflexión, a través del enjuiciamiento teleológico, le permite a

11 Cito la obra por la paginación de la edición original. 
Kant avistar un tipo de estructura de comprensión que posee, sin duda, un alcance mucho más general. Así lo muestra el hecho de que, en diversas variantes, resulta recurrente también en el tratamiento ampliado y radicalizado de los fenómenos de comprensión que llevan a cabo posteriormente autores situados en la perspectiva propia de la tradición hermenéutica, desde Schleiermacher y el romanticismo alemán hasta el pensamiento contemporáneo, en particular, en autores como Heidegger y Gadamer. En efecto, lo que Kant tematiza en el tratamiento de $K U$, a partir del caso específico de los «fines de la naturaleza», es una estructura de comprensión de carácter proyectivo-anticipativo que muestra importantes analogías con lo que, en sus diferentes posibles versiones, se conoce habitualmente bajo la denominación de «círculo del comprender» o bien del «círculo hermenéutico». El enjuiciamiento teleológico, sobre la base de la referencia proyectiva a la totalidad anticipada en la idea y a la luz de lo así anticipado, permite, advierte Kant, un nuevo tipo de consideración que es el que hace posible el acceso comprensivo a aquello que, como la totalidad organizada constitutiva del ser vivo, jamás podría ser adecuadamente concebido en términos puramente mecánicos. En rigor, hay que hablar aquí de una peculiar «ida y vuelta» entre lo proyectivamente anticipado en la idea y lo dado en el acceso perceptivo-constatativo. En efecto, como Kant enfatiza reiteradamente, allí donde se trata de dar cuenta del peculiar tipo de causalidad que corresponde al nexo de finalidad, lo que aparece como causa en un primer nivel de consideración, el que corresponde al nexo de eficiencia, es lo mismo que es visto como efecto y medio, en el segundo nivel de consideración, abierto por la referencia proyectivo-anticipativa a aquello que ha de contar como su causa y su fin.

Dada la peculiaridad del tipo de acceso que tiene aquí en vista, no resulta, en modo alguno, sorprendente que Kant se vea llevado a introducir en el tratamiento del principio de la «conformidad a fin(es)» de la naturaleza de $K U$ todo un vocabulario asociado con la idea de comprensión, que no puede ser inmediatamente vinculado con la terminología técnica del conocer que predomina en el tratamiento de $\mathrm{KrV}$. Términos como einsehen y Einsicht juegan aquí 
un papel bastante destacable. Aunque no llegan a constituirse propiamente en términos técnicos, resulta altamente llamativa la frecuente recurrencia de su empleo, en contextos en los cuales se trata de dar cuenta del tipo de acceso a la naturaleza que hace posible, en la reflexión, el enjuiciamiento teleológico, marcando, a la vez, el contraste con el conocimiento propiamente dicho y enfatizando los límites de las capacidades cognoscitivas del ser humano. ${ }^{12} \mathrm{~A}$ ello habría que añadir el amplio uso no terminológico de expresiones como begreifen, verstehen e incluso Verstand, dotadas de un significado que no remite al tipo específico de prestación que Kant conecta con la noción de conocimiento, tomada en su sentido estricto. ${ }^{13}$ Las peculiaridades vinculadas con este empleo del vocabulario de la comprensión en el tratamiento de $K U$ han pasado ampliamente inadvertidas en la investigación especializada y su estudio detallado es tarea que quedaría aún por hacer. Dicha inadvertencia puede no estar desvinculada del hecho, en sí mismo bastante sorprendente, de que el intento, no pocas veces reiterado, de hallar en $K U$ algo así como el «Kant hermenéutico» haya buscado orientación, predominantemente, a partir del tratamiento del juicio de gusto llevado a cabo en la primera parte de la obra, en particular, al hilo de nociones como la de gusto, la de sentido común, etc., y no, en cambio, a partir del tratamiento del juicio teleológico de la segunda parte, donde la discusión hace aflorar con mucho mayor nitidez algunas de las estructuras más características del acceso comprensivo al mundo. ${ }^{14}$

12 Así, para el empleo de einsehen en el marco del tratamiento del juicio teleológico, véase, por ejemplo, § 62 p. 275, § 64, p. 284, § 65 p. 295, § 66 p. 296, § 68 p. 306, § 71 p. $317, \S 73$ p. 327, § 77 p. $350, \S 78$ p. 362, § 84 p. 396 nota, § 91 p. 465; para Einsicht, véase § 72 p. $323, \S 75$ p. $338, \S 77$ p. $353, \S 78$ p. $354, \S 80$ p. $368, \S 85$ p. $401, \S 87$ p. 422 nota, § 89 p. $442, \S 91$ p. 464.

13 Para el empleo de los términos verstehen y Vertand en el sentido amplio que remite a la noción de comprensión, en el marco del tratamiento del juicio teleológico, véase, por ejemplo, $\S 72$ p. 323 , $§ 77$ p. 345 ss., etc.

14 En su valiosa investigación sobre el papel de la imaginación en la concepción de $K U$, R. Makreel ha llamado la atención sobre el papel que juega la anticipación imaginativa de totalidad en el ámbito específico de la experiencia estética (Makreel, 1990: caps. 3-5). El abordaje de Makreel tiene la rara virtud de poner de relieve un importante elemento de continuidad entre el tratamiento del juicio de gusto y el tratamiento del juicio teleo- 


\section{El nexo entre teleología y teología}

Para terminar, añado una breves indicaciones acerca del modo en el que Kant intenta hacer justicia a la dimensión propiamente teológica que la consideración teleológica de la naturaleza acarrea consigo necesariamente, allí donde, proyectada más allá del ámbito de competencia propio de la ciencia natural (Naturwissenschaft), es llevada a su término último en la reflexión.

En el $\S 68$ de $K U$, Kant distingue dos tipos de principios de una ciencia, a saber: principios internos (innerlich, einheimisch, principia domestica), y principios fundados en conceptos que encuentran su lugar fuera de esa ciencia, es decir, principios externos (auswärtig, principia peregrina). Las ciencias que contienen principios del último tipo asumen, como base de sus «proposiciones doctrinales» (Lehrsätze), ciertas «proposiciones subsidiarias» (Lehnsätze, lemmata), lo cual quiere decir que adoptan de una ciencia diferente un determinado concepto y, con ello, también un cierto fundamento de su propio ordenamiento ( $K U: 304$ s.). Ahora bien, cada ciencia debe configurar por sí misma, explica Kant, un sistema y, como tal, debe presentar una cierta unidad arquitectónica. Por lo mismo, una determinada ciencia no puede ser presentada como mera parte de una ciencia diferente, sino que cada una debe constituir primero una cierta totalidad, para que luego, en un segundo momento, se pueda dar cuenta de los puentes que permiten vincular, en ambas direcciones, dos o más ciencias diferentes (KU: 305). En el caso concreto que concierne a las relaciones entre ciencia natural y teología, lo dicho basta para descalificar, piensa Kant, el socorrido procedimiento de doble vía en virtud del cual, por una parte, se introduce el concepto de Dios en la ciencia natural, con el objetivo de hacer explicable la presencia de la

lógico, que concierne, justamente, a la presencia, en uno y otro caso, de prestaciones comprensivas que poseen una estructura análoga, al menos, desde el punto de vista que se vincula con la función posibilitante que desempeña el momento proyectivoanticipativo. En cambio, en su influyente discusión crítica de la concepción de $K U, H .-G$. Gadamer no ha explotado especialmente estas posibilidades interpretativas, al poner el énfasis, sobre todo, en lo que sería la indebida "subjetivización" de la experiencia estética (supuestamente) llevada a cabo por Kant (Gadamer, 1990 [1960]: 48 ss. [39 ss.]) 
«conformidad a fin(es)» en la naturaleza, mientras que, por la otra, se echa mano de esa misma «conformidad a fin(es)» presente en la naturaleza, para probar la existencia de Dios. Con tal modo de proceder, se priva a ambas ciencias de la necesaria consistencia interna y, a través de un razonamiento engañoso, se introduce inseguridad en ellas, al desdibujar los límites que las separan (KU: 305).

Por el contrario, explica Kant, la expresión «fin de la naturaleza» tendría la ventaja de prevenir esa posible confusión, en la medida en que evita la superposición del enjuiciamiento teleológico de los objetos de la naturaleza, a la que da lugar la propia ciencia natural, con la consideración de Dios, más precisamente, con lo que sería una «derivación teológica» (theologische Ableitung) del orden presente en la naturaleza $(K U: 305)$. La confusión derivada de superponer lo que mienta la expresión «fin de la naturaleza» con lo que sería la presencia de un «fin» $\mathrm{u}$ «objetivo» divino (göttlicher Zweck) en el ordenamiento natural no resulta irrelevante desde el punto de vista epistemológico. Tampoco se justifica por razones de mayor utilidad y adecuación a lo que se esperaría de un alma piadosa (fromme Seele), dado que, en definitiva, no se trataría sino de poder derivar la presencia en la naturaleza de formas «conformes a fin» a partir de un creador del mundo que obra sabiamente (weiser Welturheber) ( $K U$ : 305 s.). Por el contrario, desde el punto de vista metódico, hay que proceder aquí, piensa Kant, según una secuencia de pasos bien diferenciados. En primera instancia, hay que atenerse al sentido propio de la noción de "fin de la naturaleza", pues, antes de preguntarnos por la causa de la naturaleza misma, ya encontramos en ella y en el curso de su despliegue generativo "productos" de esa índole, que son producidos según leyes empíricas conocidas. La ciencia natural debe enjuiciar los objetos presentes en ella según esas leyes y, por lo mismo, debe buscar también en la propia naturaleza la causalidad que da cuenta de ellos, según la regla de los fines (nach der Regel der Zwecke). En consecuencia, la ciencia natural no debe sobrepasar su límite, para dar cabida en su interior, en calidad de principio, a aquello a cuyo concepto no puede adecuarse jamás ninguna experiencia y a lo cual solo se puede recurrir legítimamente, una vez que la propia ciencia natural ya está completada (KU: 306). 
Para mantenerse en sus propios límites, por tanto, la física hace completa abstracción de la pregunta de si los fines de la naturaleza son fines intencionales o no-intencionales (absichtlich oder unabsichtlich), porque, de lo contrario, se entrometería en un asunto ajeno, a saber: el asunto propio de la metafísica (KU: 307). Inversamente, cuando se habla de la «conformidad a fin(es)» de la naturaleza y la materia «como si» fuera intencionada, no se trata tampoco de una genuina atribución de intenciones a algo que es inanimado o privado de voluntad, sino que tal modo de hablar hace referencia tan solo a la función de un principio de la facultad del juicio en su uso reflexivo, y no determinante: el recurso a dicho principio no implica, por tanto, la introducción efectiva de un nuevo tipo de causalidad, sino que solo hace posible, desde el punto de vista del uso de la razón, un nuevo tipo de indagación, diferente de aquella que se vale exclusivamente de leyes mecánicas (KU: 308). Por ello, en la física, cuando se recurre a la reflexión teleológica, se habla legítimamente de cosas tales como la «sabiduría» de la naturaleza, de su «austeridad» (Sparsamkeit), de su «cuidado previsor» (Vorsorge), de su «carácter benefactor» (Wohltätigkeit), etc., sin que ello pretenda convertirla en un ser dotado de entendimiento, pero sin aventurarse tampoco, por ese modo mero de hablar, a postular otro ser diferente, dotado de entendimiento, que fuera su autor (Werkmeister). Esto último sería sencillamente desmesurado (vermessen), pues con el mencionado modo de hablar solo se pretende designar un tipo diferente de causalidad de la propia naturaleza, por medio de una analogía con la causalidad que nosotros mismos poseemos en el uso técnico de la razón, y con el solo fin de tener presente la regla según la cual debe proceder la indagación de determinados productos de la naturaleza (KU: 309).

La razón por la cual la teleología habitualmente no se incluye como parte de la ciencia teórica de la naturaleza, sino que se emplea, más bien, como propedeútica o tránsito a la teología tiene, por lo tanto, un alcance fundamentalmente metódico: se trata de mantener la consideración estrictamente física dentro los límites de lo que puede ser observado y experimentalmente constatado. Sin embargo, la organización de los seres organizados, en tanto fin interno de la naturaleza, sobrepasa ya infinitamente toda posibilidad 
de una exposición semejante por medio del arte. Y en el caso de las configuraciones o procesos naturales que -se supone- poseen una «conformidad a fin(es)» exterior, tales como los vientos, las lluvias, etc., la física se limita a explicar su mecanismo, pero no puede exhibir su referencia a fines, en la medida en que ésta tuviera que ser una condición que pertenece necesariamente a la correspondiente causa, ya que la necesidad del nexo (Verknüpfung) concierne, en este caso, exclusivamente al enlace (Verbindung) de nuestros conceptos, y no a la propia hechura (Beschaffenheit) de las cosas (KU: 310). Esta restricción metódica del ámbito de competencia propio de la ciencia natural, a juicio de Kant, no solo no limita a la reflexión teleológicamente orientada en sus posibilidades de despliegue, sino que, en rigor, más bien, la libera, para que pueda seguir así su propia línea de desarrollo natural, pero sin pretender por ello alcanzar un tipo de conocimiento que ya no resulta posible, como tal, más allá del ámbito de la experiencia. En rigor, la facultad del juicio se ve impulsada, siguiendo su propia máxima, a proseguir su camino de despliegue, porque la naturaleza misma le proporciona la ocasión para ello. La mera máxima de la facultad del juicio, explica Kant en el $\S 72$ de $K U$, donde evalúa críticamente las posibilidades del realismo y el idealismo como sistemas de la teleología, nos basta ya para poder seguir adelante con la indagación de la naturaleza, tratando de llegar, dentro de los límites de las fuerzas humanas, hasta sus secretos más escondidos (KU: 319 s.). Pero, justamente, este mismo hecho, es decir, el hecho de que podamos progresar de ese modo en la indagación de la naturaleza, puede verse ya, al mismo tiempo, como un cierto barrunto (Ahnung) de nuestra razón o bien como un «guiño» (Wink) de la propia naturaleza: nos permite advertir que, por medio del concepto de causas finales, podemos ir más allá de la naturaleza misma y conectarla con el punto más alto de la serie de las causas, si dejáramos de lado, al menos, por un momento, la investigación de la propia naturaleza, para averiguar a dónde nos conduce ese «forastero» (Fremdling) que irrumpe en el mismo seno de la ciencia natural: el concepto de los «fines de la naturaleza» (KU: 320).

El cambio de dirección en la indagación que da cuenta del tránsito desde la ciencia natural hacia la metafísica y la teología, siguiendo 
el hilo de la reflexión teleológica, viene, pues, sugerido e incluso motivado por una toma de conciencia que presenta dos aspectos, como su anverso y su reverso, a saber: el referido al carácter trascendente de algunos de los conceptos a los que debe recurrir necesariamente la propia indagación de la naturaleza, y el referido a los límites internos que le están trazados de antemano a la propia ciencia natural, en su campo de competencia. Como lo muestra el posterior desarrollo de la argumentación en el § 75, Kant asume, en definitiva, que la única manera de hacer comprensible, en su origen, el orden de la naturaleza, que en su existencia misma se revela como accidental/contingente, reside, tanto para el entendimiento vulgar como para el filosófico, en la referencia a un ser que existe fuera del mundo y que es su causa inteligente. La reflexión teleológica no puede hallar, pues, ninguna otra vía de clausura para su movimiento de despliege que la que conduce a la teología (KU: 335). Por lo mismo, todo aquello que, en el marco de la consideración meramente física, puede tratarse en términos de simple teleonomía, dejando metódicamente fuera de consideración la pregunta por su origen último, no puede ser comprendido cabalmente sino cuando se lo reinterpreta, en la reflexión, en términos de las condiciones que exige una genuina teleología. Y ello, ya por la sencilla razón de que una genuina comprensión del orden natural que se ofrece en la experiencia no puede eludir jamás, de modo definitivo, la pregunta por el origen último de dicho orden. Más aún, el posterior tratamiento del problema de la existencia de Dios, por medio de la discusión del argumento físico-teológico (§84-§86) y el argumento ético-teológico (§86-§89), muestra que, bajo debida consideración de los límites propios de la peculiar forma del «tener por verdadero» (Fürwahrhalten) que caracteriza a lo que llama el «creer práctico» (praktischer Glaube) (\$90-\$91), Kant no abandona jamás la convicción fundamental que lo sitúa, de hecho, en el seno de la corriente central del pensamiento metafísico y teológico tradicional, a saber: la convicción de que solo una perspectiva reflexiva radicalmente ampliada, que incluya también la referencia al orden suprasensible correspondiente a los fines de la moralidad, puede hacer posible una comprensión radical del orden natural dado en la experiencia sensible. Tal orden 
se presenta así, ante la reflexión, como un sistema de fines que queda necesariamente vinculado, en su origen y su razón últimos, a un intelecto creador infinito, que, como tal, debe poseer también necesariamente todas las características propias de la personalidad moral.

\section{Referencias bibliográficas}

DesChene, D. (2001). Spirits and Clocks. Machine and Organism in Descartes. Ithaca-London: Cornell University.

Gadamer, HG. (1990). Wahrheit und Methode. Grundzüge einer philosophischen Hermeneutik. 6ta. ed. Tübinga: Mohr Siebeck.

Kant, I. (1990). Kritik der praktischen Vernunft. H. Klemme y K. Vorländer, eds. Hamburg: Felix Meiner Verlag.

. (2001). Kritik der Urteilskraft. H. Klemme y P. Giordanetti, eds. Hamburg: Felix Meiner Verlag.

Makreel, R. (1990). Imagination and Interpretation in Kant. The hermeneutical Import of the Critique of Judgement, Chicago: University of Chicago Press.

McLaughlin, P. (1989). Kants Kritik der teleologischen Urteilskraft. Bonn: Bouvier Verlag.

Rossi, G. (2011). El azar según Aristóteles. Estructuras de causalidad accidental en los procesos naturales y en la acción. Sankt Augustin, Alemania: Academia Verlag.

Vigo, A. (2006). “Reflexión y juicio”. En Diánoia LI (57): 27-64.

Vigo, A. (2010). "Explicación causal y holismo de trasfondo en la filosofía natural de Aristóteles”. En Kriterion 51 (122) (Bello Horizonte): 587-615.

Wieland, W. (1970). Die aristotelische Physik. Untersuchungen über die Grundlegung der Naturwissenschaft und die sprachlichen Bedingungen der Prinzipienforschung bei Aristoteles. 2a ed. Göttingen: Vandenhoeck \& Ruprecht.

Zammito, J. (1992). The Genesis of Kant's Critique of Judgement. Chicago-London: The University of Chicago Press. 